\title{
Doing what with whom? Stakeholder analysis in a large transdisciplinary research project in South-East Asia
}

\author{
Joachim H. Spangenberg ${ }^{1,2} \oplus$ - K. L. Heong ${ }^{3,4} \cdot$ Anika Klotzbücher $^{1,6} \cdot$ Thimo Klotzbücher $^{5,6} \cdot$ Quynh Anh Nguyen ${ }^{7}$. \\ Vera Tekken $^{8} \cdot$ Dao Thanh Truong $^{7} \cdot$ Manfred Türke $^{9,10,11} \cdot$ Josef Settele ${ }^{1,9,12}$
}

Received: 22 March 2017 / Revised: 22 June 2017 / Accepted: 26 June 2017 / Published online: 13 February 2018

(c) The Author(s) 2018. This article is an open access publication

\begin{abstract}
The transdisciplinary research project LEGATO analysed the combined generation of provisioning, regulating and cultural ecosystem services in wet rice agriculture in South-East Asia and applied ecological engineering to future-proof it against global change and environmental pollution challenges. Due to its transdisciplinary character and the sheer size, a systematic stakeholder involvement was inevitable. Starting with stakeholder identification by snowballing from a limited number of contacts, we derived a multi-level stakeholder analysis and tried to involve those identified as relevant. Applying different means and aiming at different depth of involvement, the effort can be judged successful. The paper describes the methods used to identify and classify stakeholders, and key elements of the stakeholder management, guided by the BiodivERsA Stakeholder Activation Handbook. While on the local level, farmers and extension workers turned out to be influential and interested stakeholders in both countries, as well as local ( $\mathrm{PH})$ or provincial authorities (VN), differences were manifest on higher levels due to the divergent institutional setting. National-level agents were hard to get interested in both countries, and influential agents along the production chain, including middle men, were not really interested in collaboration.
\end{abstract}

Keywords Stakeholder identification $\cdot$ Stakeholder analysis $\cdot$ Stakeholder management $\cdot$ LEGATO

Joachim H. Spangenberg

Joachim.Spangenberg@ufz.de

1 Department of Community Ecology, UFZ - Helmholtz Centre for Environmental Research, Theodor-Lieser-Str. 4, 06120 Halle, Germany

2 Sustainable Europe Research Institute SERI Germany e.V., Vorsterstr. 97-99, 51103 Cologne, Germany

3 IRRI - International Rice Research Institute, DAPO 7777, Los Baños, Metro Manila, Philippines

4 Zhejiang University, 38 Zheda Rd, Xihu Qu, Hangzhou Shi 310027, Zhejiang Sheng, People's Republic of China

5 Department of Soil Physics, UFZ - Helmholtz Centre for Environmental Research, Theodor-Lieser-Straße 4, 06120 Halle, Germany

6 Soil Science and Soil Protection, Martin Luther University of Halle-Wittenberg, Von-Seckendorff-Platz 3, 06120 Halle, Germany
7 Institute of Policy and Management (IPAM), VNU-University of Social Sciences and Humanities, No. 336, Nguyen Trai Street, Thanh Xuan District, Hanoi, Vietnam

8 Ernst-Moritz-Arndt-University Greifswald, Friedrich-Ludwig-Jahn-Str. 16, 17487 Greifswald, Germany

9 iDiv, German Centre for Integrative Biodiversity Research, Halle-Jena-Leipzig, Deutscher Platz 5e, 04103 Leipzig, Germany

10 Terrestrial Ecology Research Group, Department of Ecology and Ecosystem Management, Technical University of Munich, Hans-Carl-von-Carlowitz-Platz 2, 85354 Freising, Germany

11 Institute of Biology, Leipzig University, Johannisallee 21, 04103 Leipzig, Germany

12 Institute of Biological Sciences, University of the Philippines Los Baños, College, 4031 Los Baños, Laguna, Philippines 


\section{Introduction}

This paper describes the stakeholder analyses as conducted as part of the LEGATO research project. LEGATO was an international consortium of 21 research institutions from six countries and two international organisations, involving about 80 scientists, 400 farmers and 20 further stakeholders. The project analysed the interdependence of provisioning, regulating and cultural ecosystem services in irrigated rice agriculture and their importance for the local population in seven regions in the Philippines and Vietnam (Settele et al. 2015; this issue).

The sheer size of the project and the project' multiple objectives addressing different dimensions of livelihood improvements under the conditions of global change (Spangenberg et al. this issue) required a truly transdisciplinary research design (Görg et al. 2015). Within a transdisciplinary project design, the co-development of research questions and the subsequent co-production of knowledge not only across scientific disciplines but also between science and non-science is decisive (Görg et al. 2014). This in turn requires identifying and activating stakeholders as knowledge bearers in co-decision processes. While integrating holders of local knowledge might be relatively easy in small-scale projects due to their usually high intensity of communication, the situation is different for research projects of a larger scale such as LEGATO; thus, a systematic approach to stakeholder involvement was considered necessary.

The message of LEGATO was to inform about the benefits from ecological engineering applied to wet rice agriculture, propagate its implementation and support demonstration projects, combined with training (seminar and field visits) and advice during the implementation. Ecological engineering includes first of all a significant reduction in insecticide spraying and a complete ban on it in the first 40 days after transplanting (leaf damages occurring in this period do not translate to yield loss because of plant compensation). Spraying undermines biological control services and can lead to severe yield losses from secondary pests (Heong 2009; Heong et al. 2015). Combined with additional measures, it also reduces weed frequency, diseases and pest infestations. Such measures are for instance optimising the distance between seedlings as on the one hand increased distances between seedlings is a technique used to reduce diseases, such as sheath blight by reducing humidity (Wu et al. 2015), however, not so much for insect pest inter plant movements as they can fly or hop rather long lengths. On the other hand, there is an upper limit to the inter plant distance as less plants per $\mathrm{m}^{2}$ reduces the harvest and tends to increase weeds, and a lower one as very close planting will reduce tillers per seedling, with a distance of about $20-25 \mathrm{~cm}$ maximising tillers $/ \mathrm{m}^{2}$. Another parameter to be optimised in such a multi-factorial land management strategy is fertiliser use. While at low levels there is a significant positive impact on yields (with the effect influenced by soil conditions), there is also a limit reaching an asymptote with diminishing returns. In fact excess fertilisation will bring about more pests and diseases, as the ecological fitness of pests increases with the increase in fertilisation (Lu and Heong 2009). Thus, fertilisation (preferably with organic fertiliser) should be reduced to the level of plants' effective nutrient take-up. If successfully implemented, farmers profit by reducing seeds, fertiliser and pesticides without losing harvest (Huan et al. 2005; Gurr et al. 2016; Van Sinh et al. this issue).

The stakeholder analysis (identifying influential and interested stakeholders, and their respective level of motivation to participate) started in the preparation phase of the project when we interviewed a selection of the immediately obvious stakeholders (in particular local researchers, extension staff and farmers). They gave hints at additional stakeholders to be included in a snowballing approach and helped to refine the draft research questions, aligning them with stakeholder needs and problem perceptions. The analysis served as the basis for stakeholder management, the process of informing and involving stakeholders. Both processes were continued throughout the 5 years of project duration, the analysis being updated and complemented whenever new insights were available.

One factor making analyses more than a one-off exercise is the changes in relevant stakeholders and their roles or motivations over time, be it for changes in the socio-economic environment, or be it due to different modes of work in different project phases. Accommodating such changes requires a continuous openness for different stakeholders' inputs and different ways of involving them (Spangenberg et al. 2015a).

To realise the intention of involving as many as possible relevant stakeholders, they must be analysed regarding their relevance and motivation, and the kind of involvement planned and pursued must be based on this analysis. Relevance regarding the project success has two key components: what the respective stakeholders can contribute, positively and negatively, to the project success defined based on the co-designed research questions, and what they are willing to contribute. Thus, after the identification of potentially relevant persons or groups, investigating their motivation was crucial, resulting in a need for permanent observation in order not to miss intrinsic or extrinsic changes in the motivation and willingness to act for or against the project.

Furthermore, the project coordination was aware that interventions in the prevailing local systems would interfere with existing conflicts and could potentially spark new 
ones. Recognising such risks the project explicitly took into account the particular sociocultural contexts from the very outset to minimise unintended side effects and achieve what might be called "sociocultural sustainability". A condition for this is to monitor not only the project success factors, but also be on lookout for potential unintended and unexpected negative effects. They might occur, for instance, by the project helping to optimise one ecosystem service at the expense of another, locally important one, not recognised by the experts, or by interfering with the prevailing distributional mechanisms and potential conflicts (Förster et al. 2015). This may be necessary in order to break up existing "lock-in situations", for example, to substitute ecological intensification and ecological engineering for high-input farm management systems, but this needs to be pursued carefully (Spangenberg et al. 2015b). Any such intervention will have supporters and adversaries, making any project dealing with objects of local importance-regardless of its intentions-an agent in local and regional conflicts; it will unavoidably be attributed the role of an agent in its own right, like it or not. As becoming an agent in local processes is unavoidable, it is better to shape the role deliberately than it being attributed by others without the project influencing the perceived role and the resulting expectations-which can easily lead to otherwise unwarranted disappointments undermining the project's success (Falck and Spangenberg 2014). Thus, expectation management, in particular having an exit strategy and communicating it early on, is crucial for project success, and stakeholder management is one of the essential means for it, requiring a permanent bidirectional flow of information.

This brief reflection has shown that stakeholder analysis is the first step towards stakeholder management which it is not a one-off exercise at the beginning of a project but needs to be a continuous process starting before the project and lasting at least to its very end. In LEGATO, the bottomup selection of stakeholders and the rather systematic communication, in many cases including repeated face-to-face meetings, were decisive for the success of the project, success being characterised by mutual learning. The transdisciplinary approach of integrating new questions emanating from local partners into the research agenda enriched the scientific conduct, and once recognised by local participants (again a communication task) strengthened their motivation to accept and support the research work (e.g. scientists entering their fields and extracting some plants or soil) and the subsequent implementation of the results.

Following this approach, section two describes the methodology of stakeholder analysis. Section three presents results, describing which stakeholders were chosen to be involved in the project, why and how. Section four discusses the outcome, the participation realised against the real-world odds, and the difficulties encountered both on the side of the project and on the stakeholders' sides (in plural due to the diversity of their positions and the resulting conflicts, Förster et al. 2015). Section five draws some conclusions for improving the stakeholder involvement in future large research projects.

\section{Method}

The description of stakeholder work basically builds upon the Stakeholder Activation Handbook published by BiodivERsA (Durham et al. 2014). The first step suggested by this guidance is a classification of stakeholders according to their interest and their influence (see Table 1 for the documentation scheme). To find out who might be a relevant representative of which category, we applied a snowballing procedure, starting with some local contacts amongst farmers, local business, administrators, scholars and politicians and followed their advice whom else to involve. The process led up to national policy makers in the Philippines and to several provincial administrators in Vietnam.

The stakeholders identified this way were interviewed, either individually (open interview) or in groups (guidelinesupported, semi-qualitative interviews). Interviews in the Philippines were mostly conducted in English (due to the country's former status as US colony still most Filipinos speak English), in Tagalog, the common language, or, in the mountain region, in Ilokano und Ifugao, in the latter cases with a translator from the project team. In Vietnam, all interviews had to be translated by Vietnamese project staff. Although in both countries no external translators were used, it cannot be excluded that the translation modified the questions asked (e.g. due to cultural taboos or other concerns) and the answers given: in particular in Vietnam in interviews with farmers suspicion about potential non-confidentiality may have influenced the statements given (although we observed no indications of such effects).

The interviews were held in all LEGATO project regions, i.e. in three provinces in the Philippines (Laguna, Nueva Ecija and Ifugao), and in four provinces in Vietnam (Tien Giang, Hai Duong, Vinh Phuc and Lao Cai), plus in the capital cities Hanoi and Manila (individual stakeholder interviews). In total, we held more than 150 individual interviews and more than 20 group interviews with about 400 participants. Additional group and personal interviews were conducted in the early phase of the project to identify the most suitable locations for the final project sites. The overall objective of the interviews was, next to the assessment of biological capacity of rice fields and their surroundings (for empirical data, see Fried et al. this issue), to evaluate the potential and acceptance of ecological engineering as a strategic tool of sustainable land use in the investigated regions, given their specific cultural characteristics, socio-economic 
Table 1 Classification of stakeholders according to influence and interest, with resulting activation forms and strategies (from Durham et al. 2014)

\begin{tabular}{|c|c|c|}
\hline 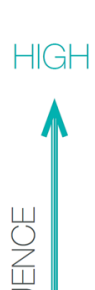 & $\begin{array}{l}\text { Involve } \\
\text { Keep these stakeholders adequately } \\
\text { informed and maintain regular contact to } \\
\text { ensure no major issues are arising. }\end{array}$ & $\begin{array}{l}\text { Collaborate } \\
\text { These stakeholders are essential to the } \\
\text { project and must be fully engaged with. Enlist } \\
\text { their full help, create partnerships, galvanize } \\
\text { support of the project, and make the greatest } \\
\text { effort to keep them satisfied. }\end{array}$ \\
\hline $\begin{array}{l}\stackrel{\amalg}{\Xi} \\
\text { LOW }\end{array}$ & $\begin{array}{l}\text { Inform } \\
\text { Monitor these stakeholders and keep them } \\
\text { adequately updated as and when required, } \\
\text { tailoring communications to meet stake- } \\
\text { holder needs. }\end{array}$ & $\begin{array}{l}\text { Consult } \\
\text { Provide these stakeholders with enough infor- } \\
\text { mation and interaction to keep them updated } \\
\text { and to address their concerns, but do not } \\
\text { overwhelm them with too much information. }\end{array}$ \\
\hline \multicolumn{3}{|c|}{ LOW } \\
\hline
\end{tabular}

situation and prevailing pesticide use patterns (for empirical data, see Sattler et al. this issue). One key purpose of all early interviews was to better understand the interviewees' position and influence on project-relevant developments and to identify their respective level of interest.

To make the results from different sites comparable, two conditions have to be fulfilled: the selected interviewees should be representative of the area, and the interview procedure must be standardised. To meet the latter condition, we used guideline-supported, semi-qualitative interviews with a series of open question permitting the interviewees to articulate their position in free speech in their own language. The extended questionnaire was used by the interviewers as a support tool to make sure the same issues were addressed in a comparable context in each case. After the first phase of identifying sites, the interviews focussed on characterising sites regarding their socio-economic and sociocultural conditions, the land use situation and the contextualisation of their own life perspectives with the regional development as observed and expected. These interviews were held separate by gender, with interviewers' and translators' sex in line with the interviewees. The other condition for comparability, a representative random collection of interviewees, could not be fully guaranteed. To achieve this, it would have been necessary to gather knowledge about the living and working conditions and the motivations for pesticide use as a basis for selecting interviewees. The potential bias resulting was minimised, however, as in the course of the project usually first the areas most suitable from a biogeographical point of view were selected, and thus, the choice of interview partners was not determined by social criteria. Only after this first step, the local communities, often consisting of rice farmers with comparable livelihoods and land use strategies, were questioned about the socio-economic and cultural background in group interviews. Only then specific fields were selected in the area studied, again based on their suitability for the planned natural science experiments, and their owners were interviewed. The final choice was thus taken based on consultations of project scientists with local stakeholders. We hold that the choice of fields and thus indirectly of their owners and (interviewed in a later phase) their farm workers, driven by scientific criteria regarding suitability for experiments, contributed to minimising any socio-economic selection bias. However, it may not eliminate it in case that a relation between site locality and social status existed, unknown to the researchers.

The interview results were documented separately for the Philippines and Vietnam. While in Vietnam the political system appeared rather homogenous across the country (although the strictness of implementing central regulations by local authorities appeared more stringent in the North of the country than in the South), leading to similar patterns of influence in our four test regions, the variability between the three sites in the Philippines was higher despite dominating commonalities within the country; local specifics were noted in the analysis. 


\section{Results}

\section{Stakeholders considered and their motivations}

For agricultural production, local farmers are an obviously relevant stakeholder in all countries; changing agricultural practices is not possible without their consent. This is particularly true for a shift of prevailing input-intense agricultural practices towards more sustainable production strategies as it requires their active involvement (Sattler et al. this issue). In the LEGATO project regions, the majority of farmers showed interest in the ecological engineering approach proposed by the project team (this may not be representative for the respective groups countrywide but a result of the test site choosing process which involved acquiring farmers' acceptance). To understand their inclination for change, it is helpful to take into account how the farmers themselves characterised their situation. In many places in both countries, they complained about farming being "hard work, low income and bad reputation". While outside the mountain areas in most cases ca. $80-95 \%$ of the farmers asserted that their rice field yielded enough for family consumption, the climate conditions limited rice cultivation to one harvest per year in the mountains; $90 \%$ of the respondents there said that their rice yield was insufficient and lasted for only four to 7 months, depending on field and family size (Schneiker et al. 2016, Supplement 1.1. and about 30 own individual interviews).

As a consequence, many farmers, from high as well as lowlands-in particular in Vietnam-encouraged their children to look for jobs outside farming; farm families in both countries wanted their children to at least complete high school before starting professional work. A second effect of this self-perception was that farmers were looking for additional sources of income; earning additional money via a secondary occupation was common in all regions (70-80\%). Secondary occupations were extremely diverse with (eco-)tourism the most frequently mentioned but rarely realised preference, probably not least due to limited knowledge about what attracts tourists and what are their demands. Local tourism business was flourishing in both mountain regions, at least in the major cities Banaue (Ifugao, $\mathrm{PH}$ ) where several of the project participants produced and sold woodcarving items, and $\mathrm{Sa} \mathrm{Pa}$ (Lao Cai, VN). More remote areas were hardly accessible to tourists (let alone mass tourism), but in Sa Pa they were found to be already part of the tourism economy, as providers of merchandise and a limited number of migrant jobs. In the low lands of the Philippines and Southern Vietnam (Mekong delta region), planting fruits was quite common as a second income (Schneiker et al. 2016 and own observations).

Against this background, while reducing insecticide use was no issue of practical relevance in the traditional terrace agriculture in Ifugao with its very limited pesticide use (only occasional use as a convenience substitute for hard field work), it was an issue of high interest in all other regions. In particular, farmers in North Vietnam and smallholders and farm workers in the Philippines were most interested in the health benefits. Farmers interviewed in the Vietnamese Mekong delta reported about health problems after spraying but considered that as self-evident element of farming, while articulating a few concerns for the environment. Larger-scale farmers in the Philippine lowlands, due to their role as entrepreneurs not working in the fields themselves, asked about the economic aspects of the suggested innovation; they considered health impacts to be of relevance to their farm workers, not themselves-interviews with farm workers confirmed that. Smallholders were concerned about health impacts, and in the hilly and in particular the mountain region also about the environmental ones (Schneiker et al. 2016). Nonetheless, we did not observe public pressure for changing the agricultural practice; policy responses focussed on education and training, not on limitations and enforcement (Table 2).

Table 2 Stakeholders considered as relevant in both countries, and their motivations derived from interviews

\begin{tabular}{|c|c|c|c|}
\hline Stakeholder & Category & Reasons to involve the stakeholder(s) & $\begin{array}{l}\text { Why the stakeholder may want to be involved } \\
\text { (benefits) }\end{array}$ \\
\hline General public & End-user of products & Public support can drive implementation & Access to sufficient amounts of safe rice \\
\hline Local farmers & End-user for change & They have to implement measures & Reduced cost and work, health benefits \\
\hline Local tourism business & Business & Indirect beneficiaries offer new local jobs & $\begin{array}{l}\text { Sustenance or improvement of landscape } \\
\text { amenities, safeguarding business opportuni- } \\
\text { ties }\end{array}$ \\
\hline $\begin{array}{l}\text { Other local agribusiness } \\
\text { (suppliers, lenders, middle } \\
\text { men) }\end{array}$ & Business & $\begin{array}{l}\text { Beneficiaries of current system need to } \\
\text { change their business models }\end{array}$ & $\begin{array}{l}\text { Sustainable business model development, } \\
\text { being prepared for changing framework } \\
\text { conditions }\end{array}$ \\
\hline Farm workers & End-user & $\begin{array}{l}\text { Handling pesticides is often mostly their } \\
\text { task }\end{array}$ & $\begin{array}{l}\text { As the ones doing the spraying, they are most } \\
\text { exposed to health effects }\end{array}$ \\
\hline
\end{tabular}


In our 2-to 3-h group interviews with more than 180 farmers, separated by gender, we gathered information about the family size and village structure including education levels, work opportunities and income levels, the local identity including landscape, land use and spirituality aspects, the institutional environment, and the knowledge of species and ecosystem functions. Special attention was given to the socio-economic effects, from field size via input volumes in physical and monetary terms (in particular pesticides) to harvest (in particular rice) and income, threats perceived and relief hoped for.

Middle men play a crucial role in rural areas in both countries, in particular for smallholder farmers. They can act as suppliers of seed and pesticides (otherwise sold by local business, more or less unregulated and with no qualification tests required from shop owners and traders), lenders in case of temporary monetary problems and buyers bringing the products to the market. In the latter case, the price they pay is well below what the state owned buying stations offer, but middle men pay immediately, organise the transport at their own cost and accept lower qualities (e.g. higher water content than the state norm in the Philippines). They are important figures in the rural social fabric, and mostly highly respected. Milling is sometimes done in a local context with small equipment, usually not as full-time profession, or in regional factories rather detached from the local communities. On those higher levels, the different political and cultural systems in both countries play a larger role, and we describe their stakeholders separately.

In the Philippines (overview in Table 3), the local authorities play an important role; on the lowest administrative level, in the barangay, multiple informal structures connect the elected spokesperson group, the barangay captain and other influential inhabitants. Their support is essential for work down to earth as much as for the final implementation of outcomes; if convinced they can effectively secure progress and rule compliance in their territories. The municipal agricultural officers (MAOs) and their staff, the extension workers, are the ones who should visit each farmer several times a year and provide advice on good practice and recommendable innovations. According to their own statements, they do so eagerly; according to farmers statements, they had not received a visit for years; official figures regarding training participation should be handled with care. This creates an information flow gap which the extension staff from chemicals companies is happy to fill, with their recommendations for which pesticide to use in which quantity for which crop at which stage of the growth cycle. For instance, Schneiker et al. (2016) found that only $23 \%$ of the respondents $(N=22)$ said that they had previously received a training by governmental or research institutions on how to manage golden apple snails, an important invasive pest in both Vietnam and the Philippines, in stark contrast with government statements. Another $12 \%$ received training by pesticide companies - mostly on how to use molluscicides. Although the trust of farmers in their recommendations is limited, they are successful in selling their products.

Given the lack of transparency at least in parts of the Philippine political system, no clear picture emerged regarding the role of provincial authorities. While the national level sets monetary flows into motion, the provincial level is channelling them, not least to pet projects, but mostly with limited relevance for local agriculture. Contact to provincial political leaders (senators, governors) resulted in friendly

Table 3 Stakeholders considered relevant in the Philippines and their motivations

\begin{tabular}{|c|c|c|c|}
\hline Stakeholder & Category & Reasons to involve the stakeholders & $\begin{array}{l}\text { Why the stakeholder may want to be } \\
\text { involved (benefits) }\end{array}$ \\
\hline $\begin{array}{l}\text { Local authorities: MAO (Municipal } \\
\text { Agricultural Officer), extension } \\
\text { workers }\end{array}$ & Administration & $\begin{array}{l}\text { In charge of advising and supporting } \\
\text { farmers }\end{array}$ & $\begin{array}{l}\text { Caring for environmental quality, indirect } \\
\text { effects and health. Implementing politi- } \\
\text { cal orders }\end{array}$ \\
\hline $\begin{array}{l}\text { Local authorities (village/city and } \\
\text { barangay) }\end{array}$ & Administration & $\begin{array}{l}\text { Influential for the general mood of the } \\
\text { community }\end{array}$ & $\begin{array}{l}\text { Caring for environmental quality, indirect } \\
\text { effects and health }\end{array}$ \\
\hline Provincial authorities & Administration & $\begin{array}{l}\text { Managing subsidy flows, managing } \\
\text { infrastructure }\end{array}$ & $\begin{array}{l}\text { Improving results, finding additional } \\
\text { sources of funding }\end{array}$ \\
\hline Provincial politicians & Politics & Influence on local implementation & $\begin{array}{l}\text { Performance of province enhances per- } \\
\text { sonal reputation }\end{array}$ \\
\hline $\begin{array}{l}\text { Provincial business (rice millers, trad- } \\
\text { ers, lenders, middle men) }\end{array}$ & Business & Beneficiaries of status quo & $\begin{array}{l}\text { Limited; some may look for future-proof } \\
\text { business models }\end{array}$ \\
\hline National politicians & Politics & $\begin{array}{l}\text { Deciding on framework, infrastructure } \\
\text { etc. }\end{array}$ & $\begin{array}{l}\text { Economic development, environmental } \\
\text { policy, self-sufficiency goal }\end{array}$ \\
\hline $\begin{array}{l}\text { National/international business (rice } \\
\text { traders, seed and pesticide producers } \\
\text { and sellers) }\end{array}$ & Business & Setting prices, managing supply & $\begin{array}{l}\text { Limited; improved production would } \\
\text { reduce import volumes }\end{array}$ \\
\hline
\end{tabular}


but mostly ineffective support, as in particular guaranteed monetary or reputational gains for the province seemed to be of interest, rather than the experimental and demonstration phase. On the national level, in our (limited) interactions with Congress members, the enthusiasm was less pronounced.

As can be expected given the different political and economic systems (a market economy with a democratic system heavily influenced by family and clan structures versus a socialist market economy with blurred delineation between politics, administration and business), and the different cultural heritage (catholic former Spanish and US American colony versus culturally Buddhist former kingdom and Fench colony), the situation in the Philippines and Vietnam is significantly different.

In Vietnam (overview in Table 4), the provinces are powerful political agents, albeit within the framework set by the national leadership, and the party leadership guides and controls the administration. While due to the rather strict hierarchical structure of the political system the project neither tried nor managed to establish contacts to the national leadership, provincial leaders (party, government, agencies like the plant protection agency) were highly interested in the social and economic success of their respective province, not least as a good performance on the provincial level opens career pathways on the national level. Interestingly, while environmental concerns were not prioritised in the agricultural department, the impact of pesticides was often considered as critical to social progress, as it threatened food safety and security—environmental consciousness emerged as an indirect result of social concerns. As a consequence, national regulations, popularised by campaigns, forbid using insecticide in rice agriculture in the early growth phase. In this phase, spraying is not only unnecessary as plants recover, but it also increases the vulnerability to later stage infestations due to the damage done to biocontrol organism populations. However, international pesticide producers at least partly ignored the legal regulation (we found posters with Bayer Crop Science logos issuing diverging recommendations); if a threat of criminal charges against violators, issued by the Vietnamese government late in the project, will change the situation is not (yet) clear. National companies in the process chain include millers and traders, particularly in the Mekong Delta, which are focussed on production for the world market and thus concerned about competitiveness in cost and quality.

In Vietnam (see Table 4) as elsewhere administrations are not homogenous. Agriculture is a well-established, traditional branch of the administration core, while the tourism and culture administration seemed to be less heavyweight, being a younger administrative unit and dealing with "soft" issues. Interestingly, despite the rather strict hierarchical political system, the perception of government acts and consequently the level of compliance was found to differ significantly between North and South Vietnam: the same regulations regarding which rice varieties to plant and which pesticides to use from a climate-adapted list, differentiated per province, were described as binding rule by local authorities and farmers in the North, while in the South both described them as "government recommendations", and

Table 4 Stakeholders considered relevant in Vietnam and their motivations

\begin{tabular}{|c|c|c|c|}
\hline Stakeholder & Category & Reasons to involve the stakeholders & $\begin{array}{l}\text { Why the stakeholder may want to be } \\
\text { involved (benefits) }\end{array}$ \\
\hline Local authorities & Administration & $\begin{array}{l}\text { In charge of advising and supporting } \\
\text { farmers }\end{array}$ & Implementing political orders \\
\hline Provincial party leadership & Politics & $\begin{array}{l}\text { Without their support, no projects are } \\
\text { possible }\end{array}$ & $\begin{array}{l}\text { Success in implementing plans is career } \\
\text { enhancing }\end{array}$ \\
\hline Provincial agricultural administration & Administration & $\begin{array}{l}\text { Supervising projects, caring for farmers' } \\
\text { income security }\end{array}$ & $\begin{array}{l}\text { To match recent reorientation of national } \\
\text { policies towards quality }\end{array}$ \\
\hline Provincial plant protection officials & Administration & Specifying pesticide use guidelines & $\begin{array}{l}\text { To match recent reorientation of national } \\
\text { policies towards quality }\end{array}$ \\
\hline Provincial tourism department & Administration & $\begin{array}{l}\text { Support decisive for ecotourism devel- } \\
\text { opment }\end{array}$ & $\begin{array}{l}\text { Seeking opportunities to promote culture } \\
\text { and tourism }\end{array}$ \\
\hline Rice production chain agents & Business & $\begin{array}{l}\text { Co-determine agricultural practice as } \\
\text { buyers }\end{array}$ & $\begin{array}{l}\text { Could improve reputation and price on the } \\
\text { world market }\end{array}$ \\
\hline $\begin{array}{l}\text { National politicians (party leadership, } \\
\text { implementation by ministries) }\end{array}$ & Politics & $\begin{array}{l}\text { Deciding on development plans and pri- } \\
\text { orities, env. and health policy, export } \\
\text { earning strategy }\end{array}$ & Not accessible to projects \\
\hline $\begin{array}{l}\text { National/international business (rice } \\
\text { traders) }\end{array}$ & Business & Setting prices, defining quality demands & $\begin{array}{l}\text { Limited; quality improvement may } \\
\text { increase international market opportuni- } \\
\text { ties in the longer run }\end{array}$ \\
\hline
\end{tabular}


compliance as recommendable but voluntary. In Lao Cai, where tourism already is one of the major industries (besides mining and agriculture-an uneasy partnership), the government had realised the potential of ethnic diversity, landscapes and rice terraces to attract tourists. However, being rather uninformed about the international tourism industry, not all plans appeared realistic, but when informed about that the leadership undertook effective learning measures including national and international academics and experienced staff from other provinces and from nearby Asian tourism regions (Yunnan, PR China). Other provinces (e.g. Hai Duong with a rich cultural heritage) focussed on domestic tourism and pilgrimage, while the hope of farmers and local officials for ecotourism and agro-tourism income in a high pesticide input production system appeared somehow naïve.

\section{Categorising stakeholders by influence, interest and possible role for the project}

Not all stakeholders are equal, nor should be the way they are addressed by and involved into a project. To plan for adequate stakeholder involvement to achieve the best possible support, those who are both interested in the project and influential need to be closest associated with it (see Table 1). They had to be addressed to become collaborators; Table 5 summarises the categorisation. In the Philippines, this applied to farmers and local authorities, while in Vietnam it was farmers and the provincial authorities. The opposite group is potential stakeholders of low influence and low interest; they need to be informed, but will not significantly influence the functioning of the project.

Although the political systems in both countries are very different, the public at large falls into this category in both cases (food safety, a matter of public interest, was

Table 5 Influence-interest matrix for LEGATO stakeholders

\begin{tabular}{lll}
\hline Influence & Interest & \\
\cline { 2 - 3 } & Low & High \\
\hline \multirow{2}{*}{ Low } & Inform & Consult \\
& Public at large (VN, PH) & External experts \\
& & Provincial tourism authorities \\
& & (VN) \\
& & Media (agro-TV) (N-VN) \\
High & Involve & Collaborate \\
& Middle men (PH, VN) & Farmers (PH, VN) \\
& Rice production chain & Eminent persons in the com- \\
& agents (PH, VN) & munities (PH) \\
& National stakeholders & Local authorities (PH) \\
& (PH, VN) & Provincial agricultural and \\
& & plant protection authorities \\
& & (VN) \\
& & Media (infotainment-TV) \\
& & (S-VN)
\end{tabular}

not an issue used in the project communication). While in the Philippines the project did not find means to inform the public (neither national scale media nor local scale stakeholders were willing to engage, maybe due to the lack of financial incentives), in Northern Vietnam the high level of interest by some public TV stations led to a number of reports informing the public. In South Vietnam, special and successful efforts were undertaken to collaborate with TV stations based on earlier experience (Escalada et al. 1999; Escalada and Heong 2012; Heong et al. 2014), resulting in a TV sitcom series on ecological engineering developed together with the project which changed regional farmers' insecticide use to a measurable degree (Settele et al. 2015; Westphal et al. 2015).

For the high interest groups, the project managed to fully engage the high interest/high influence group, enlisting their full help, creating partnerships, galvanising support of the project and exploitation of its results and made great efforts to keep them satisfied. The high-interest/low-influence group was provided with sufficient information and contacted regularly to keep them updated, and to identify and incorporate their concerns without overwhelming them with too much information, in both cases meeting the objectives of stakeholder participation planning method as defined by Durham et al. (2014).

The public as a low interest, low influence group was merely informed, with several TV programs in Vietnam, tailored to meet stakeholder needs by making use of the agriculture TV, most watched in rural areas (in poor areas, however, no TV sets are available). Internet access is widely available for cell phone owners, but was not exploited by the project not least due to the limited number of smartphones owned by farmers and farm workers, and the language barriers which are also one of the limiting factors for the influence of the YouTube of IRRI, one of the project partners (Schneiker et al. 2016). This choice of means of communication is also in line with the stakeholder involvement method chosen. The most difficult group turned out to be the high-influence/low-interest stakeholders; the intention was to keep them adequately informed and maintain regular contact to ensure no major issues are arising. In reality, contacts were made but regularity could not be ensured, although information was provided and the early concepts helped avoiding that major higher-level challenges arose by integrating known concerns into the project objectives. For national stakeholders from business and administration in both countries, a series of local projects was nothing considered warranting involvement, while discussions with middle men were informative but could not motivate involvement, possibly as they saw some of their status and profit generating roles under threat by a successful transition to ecological engineering. Consequently, the stakeholder activation focussed on the high interest groups identified, 


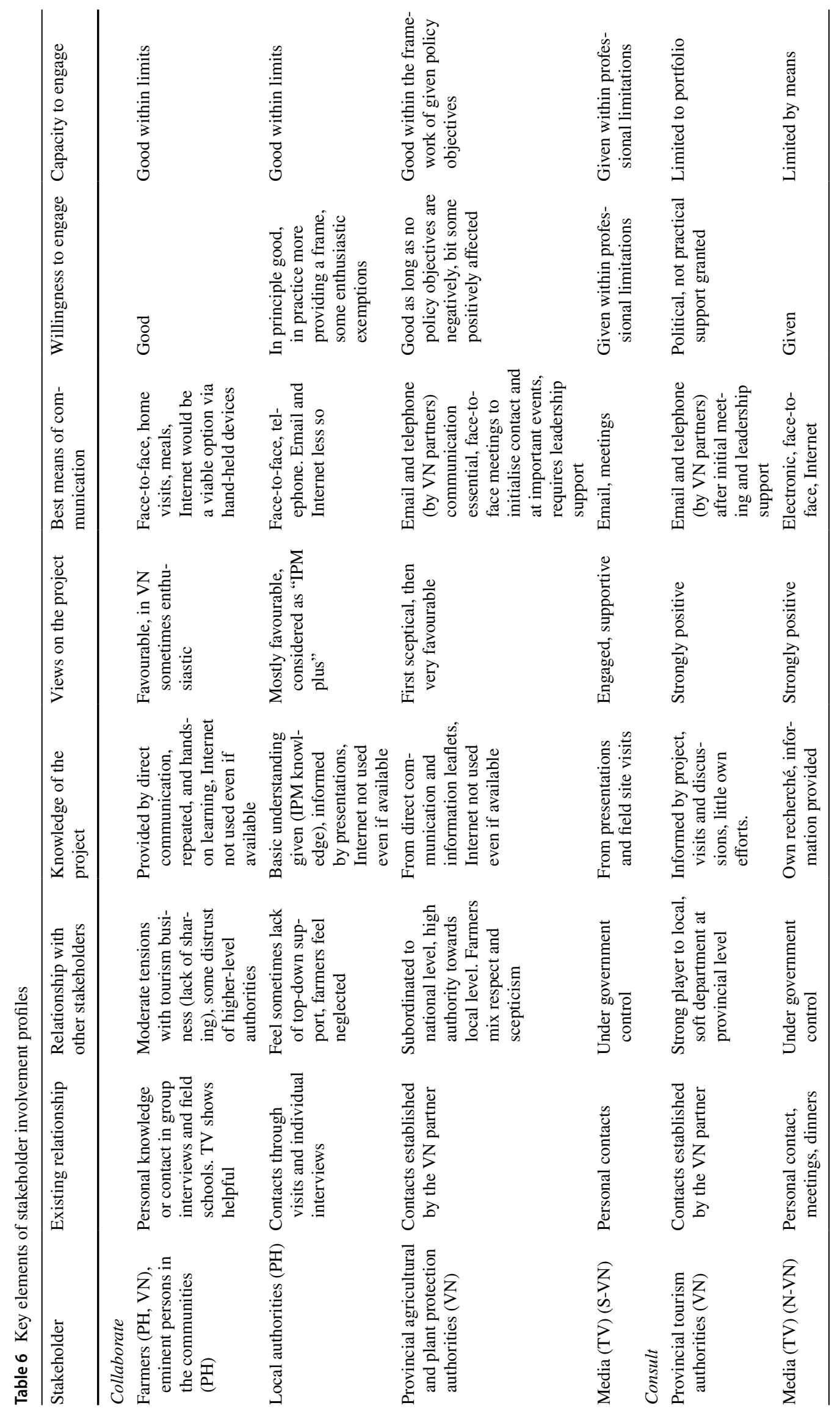


but overall the objectives defined in the BiodivERsA stakeholder engagement source by Durham et al. (2014) have been achieved.

Due to the focus on high interest stakeholders (only they are described in some detail in Table 6), all groups more closely investigated and involved had a favourable view of and attitude towards the project. They were ready to support the project with their professional means and within the limits of their competences-which is the maximum which can be expected. The basis of their engagement was, with few exceptions, the information provided by the project itself, less so in writing and more in direct presentations, discussions and informal meetings. A general experience is that-at least in Asia-contacts require face-to-face meetings: they can be prepared by other means of communication, but at least at the kick-off stage a meeting is required to start any fruitful collaboration. Such meetings must be repeated before the positive effect wanes, with a frequency depending on the kind of stakeholder (more with farmers, less with authorities). Longer established personal contacts (by one of the project partners) are an invaluable asset for any project, but require investing time and engagement.

\section{Conflicts between and within stakeholder groups}

Although all groups of collaborating and consulted stakeholders had a positive attitude towards the ecological engineering application in rice cultivation promoted by the project, conflicts between and within stakeholder groups emerged. What was detectable from the interviews in Vietnam is summarised in Table 7.

Generally speaking, the cause of open conflicts (OC, known by everyone) is cognitive conflicts resulting from differing assessments of data or facts which lead different involved parties to different conclusions (Durham et al. 2014). Such open conflicts occurred for instance within the stakeholder group of farmers caused by the differences in perception when the local farmers in the Northern Vietnamese Hai Duong province were keen to apply ecological engineering while the farmers in Sapa, Lao Cai province, in the Northern Vietnamese mountain region were not interested, stating that ecological engineering would not help them save cultivating costs.

This conflict overlaps with one based on gender differences, with the female saying that they are main labour force in agricultural activities while the men also convinced that they have most important role in agricultural work-a clear cognitive difference over largely shared experiences. Most of the females in both provinces stated that they would prefer to apply ecological engineering because it would at least partly relieve them from spraying pesticides and other chemicals in the fields, an activity perceived as having caused skin and respiratory diseases.
Opposed to that, the majority of men said that they would apply the method only if the government would give them financial support for buying seeds and fertilisers (which are used less under ecological engineering than in the current agricultural system) and compensate them if the application failed. This type of conflict occurs frequently in most of the collaborating stakeholder groups.

Hidden conflicts (HC-known only to certain people) tend to happen between groups of unequal power, when the side feeling disadvantaged does not see a benefit from bringing the conflict into the open. This was the case for the conflict between the provincial agricultural administration-whose concern is the general benefits from economic development - and two other stakeholder groups, namely the general public and local farmers. The provincial agricultural administration is directly involved in handling complaints by local people, including farmers-a vulnerable local group. However, most of the administration members emphasise the macroeconomic benefits from economic development, giving more support to enterprises' rights in disputes between businesses and people over the negative impacts of the policy of changing the politically determined and legally binding land use purpose from agricultural to other uses (see the latent conflict example below). One of the side effects of this policy is that the group of provincial agricultural administration members may get benefits (money, higher positions,...) from enterprises, to reduce the compensation money paid to farmers. This is causing the hidden conflicts between the two groups as the provincial agricultural administration in this case is acting accomplice in the conflict of interests between enterprises and famers.

Latent conflicts (LC, arising when something occurs that changes the status quo) occurred between groups of policy makers/decision makers (local authorities, provincial party leadership, provincial agricultural administration) with groups of local people (farmers, local agribusiness...) when policy objectives did not meet with their demands or had a negative impacts on their daily life. For instance in the Hai Duong province, changing the land use purpose is a means to implement the industrialisation aim set by the political leadership with the intention to improve the GDP and increase the local income and living standard in the province. In the interviews with decision makers, most of them agreed that future local investments will focus on industrial development; they hope to attract more enterprises to set up business in the industrial zone of Hai Duong. However, they do not take into account the downside of such development, like health impediments caused by industrial air and water pollution, or the impacts of this industrial policy on other sectors such as tourism (Hai Duong has some of the oldest cultural heritage sites of Vietnam and is a domestic tourism hotspot) and agriculture (labour shortage as young people move to the industry for better and better paid jobs; 
Paddy and Water Environment (2018) 16:321-337

331

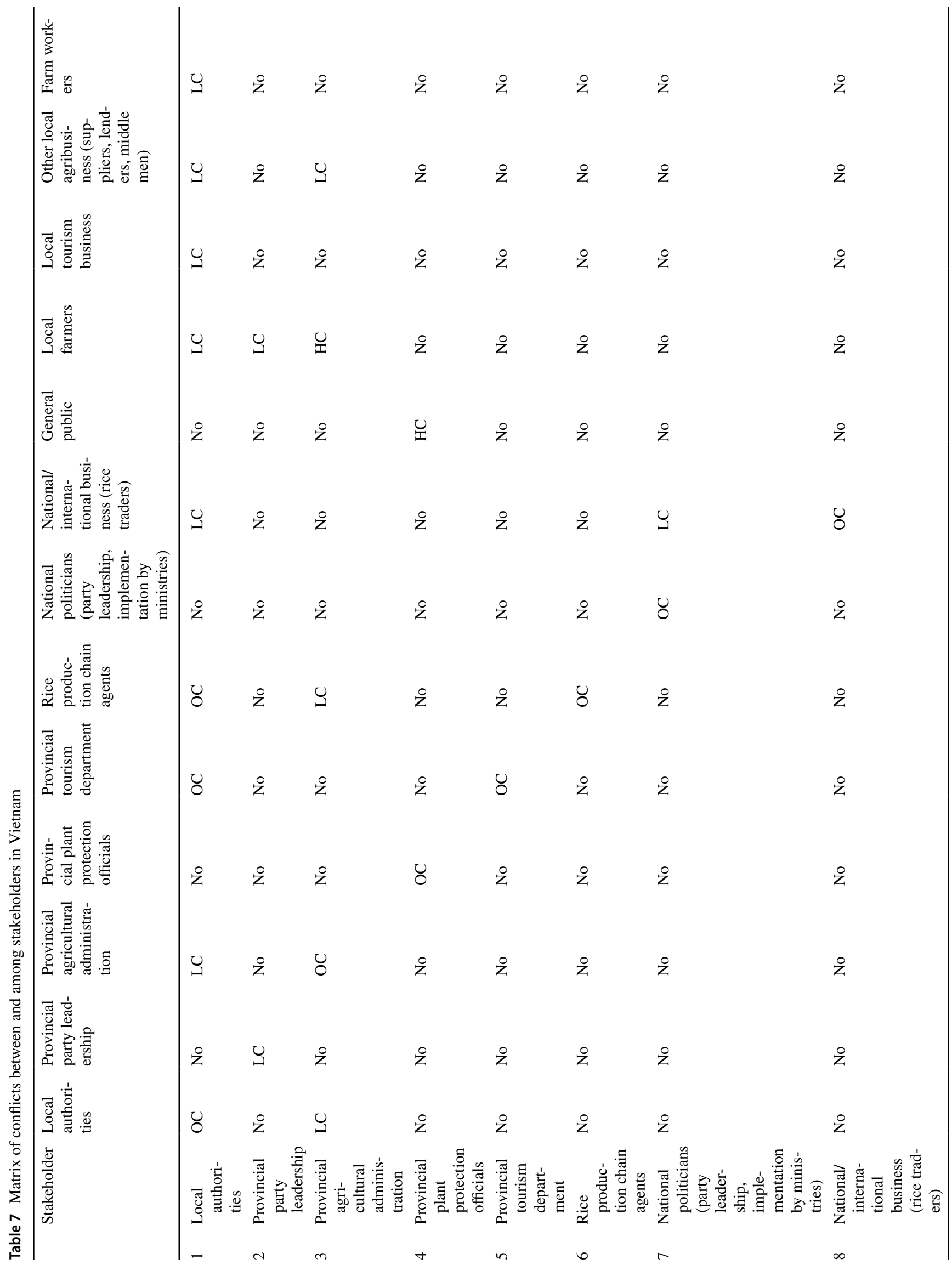

Springer 


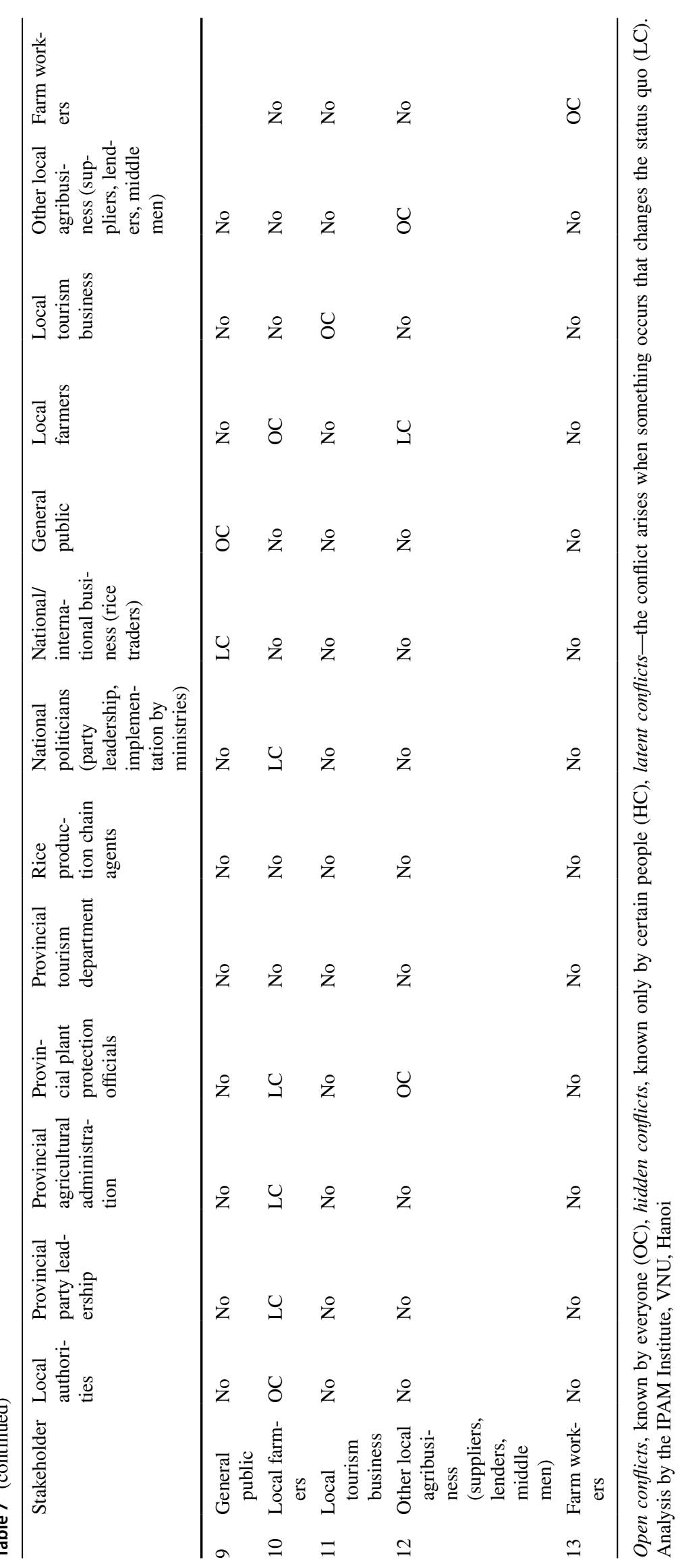


local farmers without own land become unemployed). The conflict potential is obvious and will become virulent once the side effects accumulate.

One the other hand, the same decision makers considered agriculture as a key sector with local potentials such as human resources, fertile land and suitable climate to further develop it, confirming the position of Hai Duong as an agricultural zone supplying for the demand of neighbouring provinces (Hanoi, Hai Phong, Quang Ninh). In this case, the farmers who would get direct benefits from the industrialisation policy (land compensation fee in case of conversion of land from agricultural to urban/industrial) will become the opposition groups, strongly against the decisions of policy makers in the future. Either development direction creates potential winners and losers, and thus latent conflicts.

\section{Policy participation of stakeholders}

As a result of the project communication (less so from other sources), all stakeholders approached in Vietnam saw the benefits of ecological engineering and showed a raised awareness of the necessity of and the potential for environment protection in rice production. The discussion among stakeholders and with researchers helped all of them to appreciate the opportunity for improving the environmental performance by means of ecological engineering in irrigated rice farming. The conclusions they drew and the actions they took depended on the kind and level of influence they commanded (see Table 5); we distinguish two basic types (see Table 8 for the group codes):

A top-down approach was applied by groups 1, 2, 3, 4, 5, 7 and 8 which have a medium to high level of participation in policy-making process and wield significant influence on their respective level of action and downwards from it. The advantage of this top-down approach is that priorities of the government, the collectives and communities are represented and well respected due to the fact that the planning exercise is executed by professional planners, managers and policy makers. Its disadvantage, however, is that the planning option does not necessarily satisfy the local people's desires and needs, especially not for members of the ethnic minorities living on the allocated agricultural land.

The advantage of a bottom-up approach is that the people's needs and desires are taken into account from the outset and maybe even be satisfied. This approach was chosen by groups $6,9,10,11,12$ and 13 which only have weak to medium-level participation in the policy development, implementation and evaluation process. Its disadvantage is the limitations of influence on and knowledge about agricultural land use options, as the bottom-up demands are elaborated by people who usually lack information (market information, for example) and high visibility. In addition, national benefits are sometimes inadequately defined due to a knowledge mismatch of the ordinary people and the land use requirements at the national level (Table 8).

\section{Citizen science}

A special case was the citizen science module in LEGATO (for details, see Hirneisen et al. this issue). It involved local stakeholders in Ifugao, in the Philippines mountain area in contests between schools and social groups in photographing and identifying butterfly and dragonfly species (Dem et al. this issue). We called them "the flying beauties" as many

Table 8 Policy participation level of stakeholders

\begin{tabular}{|c|c|c|c|c|c|}
\hline Group no. & Groups & $\begin{array}{l}\text { Policy-mak- } \\
\text { ing process }\end{array}$ & $\begin{array}{l}\text { Policy deci- } \\
\text { sion making }\end{array}$ & $\begin{array}{l}\text { Policy } \\
\text { implemen- } \\
\text { tation }\end{array}$ & Policy evaluation \\
\hline 1 & Local authorities & High & High & Medium & High \\
\hline 2 & Provincial party leadership & High & High & Weak & Medium \\
\hline 3 & Provincial agricultural administration & Medium & Medium & High & Medium \\
\hline 4 & Provincial plant protection officials & Medium & Medium & High & Medium \\
\hline 5 & Provincial tourism department & Medium & Medium & Medium & High \\
\hline 6 & Rice production chain agents & Weak & Weak & Medium & High \\
\hline 7 & National politicians (party leadership, implementation by ministries) & High & High & Weak & High \\
\hline 8 & National/international business (rice traders) & Weak & Weak & High & High \\
\hline 9 & General public & Weak & Weak & Medium & Medium \\
\hline 10 & Local farmers & Weak & Weak & High & High \\
\hline 11 & Local tourism business & Weak & Weak & High & High \\
\hline 12 & Other local agribusiness (suppliers, lenders, middle men) & Medium & Medium & Medium & Medium \\
\hline 13 & Farm workers & Weak & Weak & Medium & Weak \\
\hline
\end{tabular}

Analysis by IPAM Institute, VNU, Hanoi 
of them had no specific name in the local language, and of course the biological terminology was not familiar to the residents. Selecting interested schools and settlement districts (barangays) with the support of local project staff was a first step, but face-to-face contact, presenting the concept in schools and villages was essential for the successful mobilisation of participants. In this case, stimulated by the competition with the school kids, groups of elders, tourist guides and barangay leadership took part, dedicated to demonstrate that their experience compensates for youthful fitness. In the course of the event, the local leaders agreed to sustain follow-up activities as they recognised the potential usefulness of measures to preserve and showcase the richness of butterfly diversity for attracting additional, income generating tourism. Besides the competition effect, the access to up-to-date photographic equipment and the presentation of results and winners in a public ceremony with most local peasants attending were mentioned as additional incentives for participation.

In both countries, the local authorities as a group often have mostly hidden internal conflicts as well as conflicts with other groups, as they often pursue other (development) policy concepts than those preferred by the local community, or which in the Phillipines are perceived as a sink to resources earmarked for the community (corruption is commonplace on most administrative levels). Another reason for hidden conflicts can be the role of younger people earning their income outside traditional structures, who to a certain degree begin to question the authority of elders and leaders (cultural challenge in Vietnam).

\section{Discussion}

Governance of the environment and ecosystem services, as opposed to resource management, represents a shift in epistemological perspectives for the mobilisation of knowledge, from expert driven to collaborative, deliberative and discursive (Bremer 2013; Spangenberg et al. 2015a). Including stakeholders in projects, plans and policies at eye level are a condition for mobilising their knowledge in sustainability science (Spangenberg 2011) and in particular in decision making in "post-normal situations", i.e. when stakes are high, decisions urgent, facts uncertain and values disputed (Funtowicz and Ravetz 1993). To be successful, such processes must be inclusive of all knowledge systems and languages of valuation (Martinez-Alier 2008), bring together knowledge through reciprocal dialogue and allow for the negotiation of knowledge credibility, salience and legitimacy (Bremer 2013); all these conditions were given in the LEGATO project.

However, despite its benefits, the consultation of local stakeholders by higher-level decision makers is still far from routine or being self-evident. This is true even in Scandinavian countries famous for their participatory habits (Huttunen 2015), and more so in large parts of Asia (Siew et al. 2016). As a result, farmers often feel that the measures taken or suggested are incoherent with their goals and practices. One reason is that top-down policies are not always capable of taking into account local or sociocultural factors, such as the prestige associated with successfully growing difficult crops or at the margin of the production season, with higher risk but rewarded by higher market prices. As this adds to the unpredictability of weather conditions and its effects on crop yields and farming practices, one-size-fits-all regulations can only fail. Alternatives require stakeholder input to identify difficulties, but also to find ways how such challenges can be addressed (Huttunen 2015). Stakeholder involvement, if it is to go beyond symbolism and be effective, must secure stakeholders' influence on decisions to be taken, provoking hidden and open conflicts and actualising potential ones. The power shift implied by this would most probably also modify the kinds and strength of motivation. In the individual interviews we undertook, more often than not the levels of influence and of interest in local innovations appeared negatively correlated: the higher the institutional position of a stakeholder, the less important a local project tended to appear to him (higher echelons were almost exclusively male, except for the culture and tourism departments).

An exemption from this rule of thumb emerged in the later phase of the project in the Vietnam Hai Duong province: after the national leadership had decided that in future the quality of Vietnamese rice exports (which had internationally a rather mediocre reputation not least due to the high doses of pesticides used in the production) would be considered more important than the quantities (probably motivated by the premium prices paid for Thai rice in the world market), the attitude changed. Several authorities (agriculture and social administrations, pesticide authorities) offered their support; the provincial leadership considered the project as a pilot for a new production system helpful to possibly implement the orientations issued by the national leadership and announced to make the methods a standard in the province if sufficient success could be demonstrated by the project-which, however, ended before the final results could achieve the desired effect.

Beneficial constellations can emerge from lucky coincidence, as the Vietnamese example shows, but usually they do not emerge without careful planning. Evaluating European experience from the UK, Reed et al. (2014) have identified the five principles explained below, which must be given for effective knowledge exchange. Implementing them is considered to help researchers, policymakers and practitioners in environmental management work together more effectively to produce, share and apply knowledge to manage environmental change. 


\section{Design}

It is important to know what everyone involved hopes to achieve through knowledge exchange and that these aims are built into the project from the beginning. Due to a stakeholder consultation phase before the final research questions were defined, this was realised in the project.

\section{Representation}

The distinction between those who carry out research and those who use its results was made clear ex ante, so the input of the two groups could be used to help design both the research and knowledge exchange (Spangenberg et al. 2015a).

\section{Engagement}

Two-way communication and long-term trust building was encouraged between researchers and other stakeholders wherever possible, to facilitate knowledge exchange. The limited duration of the project and the roles attributed to it made expectation management and an early-on defined and communicated exit strategy a necessity (Görg et al. 2014).

\section{Generate Impacts}

To keep potential users of research engaged with the research process, there was a focus on creating tangible results as early as possible. However, accelerating the production of results has natural limitation in agricultural production systems.

\section{Reflect and Sustain}

Effective knowledge exchange is based on long-term relationships and learning, a challenge for research projects which are usually of short duration, compared to development projects. Monitoring and reflecting to improve the process was continuously undertaken. Considering ways to sustain knowledge exchange, even after project funding ends, is a challenge; in particular the deep divide between development and research agents and agencies is a major obstacle to any more continuous knowledge exchange. If research would learn from development regarding research questions and its results could thus inform development projects, and development could take over research achievements, both would benefit.

By following the BiodivERsA guidelines (Durham et al. 2014), we successfully implemented the criteria of Reed et al. (2014), creating a two-way learning process. In the almost classical systematic of Pretty (1995), the participatory processes undertaken in the LEGATO project can be classified as "functional participation", serving project goals based on genuine interaction and providing opportunities for joint decision making. The fact that in Vietnam participants had to be compensated for the time they offered does not affect this, as the amount demanded was just equivalent to the loss of earnings, and the "limited space for learning" criterion Pretty suggests for the category "participation for material interest" did not apply to the participation processes organised.
The genuine interaction led to modifications of the project structure (additional themes were picked up like tourism or the case of the Golden Apple snail which were not initially on the project agenda) and added new research questions. For instance, interviewing farmers revealed that at some of the research sites the rice straw is permanently removed from the paddy fields after harvest. This finding stimulated research on importance of rice straw decomposition as source of plant-available silicon in a Vietnamese region where low concentrations of plant-available silicon in soil might limit rice yields (Marxen et al. 2016; Klotzbücher et al. this issue). Another example is the role of the giant earth worm in the Philippines; its existence, long claimed by farmers, was confirmed by scientific observation in the course of the project, but unlike farmers suspected, it was found not to be the reason for rice terrace damages. The strong influence of small-scale local conditions, social and cultural factors illustrated also the limitations to identifying transferability potentials for research results to regions characterised by similar biophysical conditions (Václavík et al. 2016), but different sociocultural and political structures and processes. Involving local stakeholders at eye level has proven to be indispensable for effective and successful project conduct, as in the case of LEGATO. The BiodivERsa guidelines have proven their value as an excellent support and guidance tool for project planners and managers.

Acknowledgements This paper would not have been possible without the permanent and friendly support by our colleagues and collaborators, farmers, academics and decision makers, in both the Philippines and Vietnam, but also in Europe. We are also grateful to the EU BiodivERsA program for organising fruitful discussions with colleagues and for issuing the Stakeholder Engagement Handbook which helped us structuring, and to the German Federal Ministry of Education and Research BMBF which not only funded LEGATO under Grant Number FKZ01LL0917A-01LL0917O, 2010-2016, but also offered ample room for stimulating discussions with related projects in the context of the "Sustainable Land Management" Funding Measure.

\section{Compliance with ethical standards}

Conflict of interest The authors declare that they have no conflict of interest.

Open Access This article is distributed under the terms of the Creative Commons Attribution 4.0 International License (http://creativeco mmons.org/licenses/by/4.0/), which permits unrestricted use, distribution, and reproduction in any medium, provided you give appropriate credit to the original author(s) and the source, provide a link to the Creative Commons license, and indicate if changes were made.

\section{References}

Bremer S (2013) Mobilising high-quality knowledge through dialogic environmental governance: a comparison of approaches and their 
institutional settings. Int J Sustain Dev 16(1/2):66-90. https://doi. org/10.1504/IJSD.2013.053791

Durham E, Baker H, Smith M, Moore E, Morgan V (2014) The BiodivERsA Stakeholder engagement handbook. BiodivERsA, Paris

Escalada MM, Heong KL (2012) Using decision theory and sociological tools to facilitate adoption of biodiversity-based pest management strategies. In: Gurr GM, Wratten SD, Snyder WE, Read DM (eds) Biodiversity and insect pests: key issues for sustainable management. Wiley-Blackwell, Oxford, pp 199-213

Escalada MM, Heong KL, Huan N, Mai V (1999) Communication and behavior change in rice farmers' pest management: the case of using mass media in Vietnam. J Appl Commun 83:7-26

Falck WE, Spangenberg JH (2014) Selection of social demand-based indicators: EO-based indicators for mining. J Clean Prod 84:193203. https://doi.org/10.1016/j.jclepro.2014.02.021

Förster J, Barkmann J, Fricke R, Hotes S, Kleyer M, Kobbe S, Kübler D, Rumbaur C, Siegmund-Schultze M, Seppelt R, Settele J, Spangenberg JH, Tekken V, Václavík T, Wittmer H (2015) Assessing eco-system services for informing land-use decisions: a step-wise approach for place-based ecosystem service assessments. Ecol Soc 20(3):31. https://doi.org/10.5751/ES-07804-200331

Fried et al. (this issue) Plant diversity and composition of rice field bunds in Vietnam and the Philippines

Funtowicz SO, Ravetz JR (1993) Science for the post-normal age. Futures 25:739-755

Görg C, Spangenberg JH, Tekken V, Burkhard B, Truong DT, Escalada MM, Heong KL, Arida G, Bustamante JV, Chien HV, Klotzbuecher T, Marquez L, Marxen A, Manh NH, Sinh NV, Villareal S, Settel J (2014) Engaging local knowledge in biodiversity research: experiences from large inter- and transdisciplinary projects. Interdiscip Sci Rev 39(4):323-341

Görg C, Settele J, Spangenberg JH (2015) The co-production of ecosystem service knowledge: experiences from large inter- and transdisciplinary projects. GLP NEWS 11:27-29

Gurr GM, Lu Z, Zheng X, Xu H, Zhu P, Chen G, Yao X, Cheng J, Zhu Z, Catindig JL, Villareal S, Van Chien H, Cuong LQ, Channoo C, Chengwattana N, Lan LP, Hai LH, Chaiwong J, Nicol HI, Perovic DJ, Wratten SD, Heong KL (2016) Multi-country evidence that crop diversification promotes ecological intensification of agriculture. Nat Plants. https://doi.org/10.1038/nplants.2016.14

Heong KL (2009) Are planthopper problems caused by a breakdown in ecosystem services? In: Heong KL, Hardy B (eds) Planthoppers: new threats to the sustainability of intensive rice production systems in Asia. IRRI International Rice Research Institute, Los Baños, pp 221-232

Heong KL, Escalada MM, Chien HV, Cuong LQ (2014) Restoration of rice landscape biodiversity by farmers in Vietnam through education and motivation using media. S.A.P.I.E.N.S (online) 7(2): 29-35. http://sapiens.revues.org/1578

Heong KL, Wong L, de los Reyes JH (2015) Addressing planthopper threats to Asian rice farming and food security: fixing insecticide misuse. In: Heong KL, Cheng J, Escalada MM (eds) Rice planthoppers. Springer, Amsterdam, pp 65-76

Hirneisen et al. (this issue) Flying beauties-citizen science experiences in South-East Asian rice landscapes

Huan NH, Thiet LV, Chien HV, Heong KL (2005) Farmers' evaluation of reducing pesticides, fertilizers and seed rates in rice farming through participatory research in the Mekong Delta, Vietnam. Crop Prot 24:457-464

Huttunen S (2015) Farming practices and experienced policy coherence in agri-environmental policies: the case of land clearing in Finland. J Environ Policy Plan 17(5):573-592. https://doi. org/10.1080/1523908X.2014.1003348
Klotzbücher A et al. (this issue) Effects of Si fertilization on $\mathrm{Si}$ in soil solution, Si uptake by rice, and resistance of rice to biotic stresses in Southern Vietnam

Lu Z, Heong KL (2009) Effects of nitrogen-enriched rice plants on ecological fitness of planthoppers. In: Heong KL, Hardy B (eds) Planthoppers: new threats to the sustainability of intensive rice production systems in Asia. IRRI (International Rice Research Institute), Los Baños, pp 247-256

Martinez-Alier J (2008) Languages of valuation Econ Polit Wkly 43(48): 28-32. http://www.jstor.org/stable/40278233

Marxen A, Klotzbücher T, Jahn R, Kaiser K, Nguyen VS, Schmidt A, Schädler M, Vetterlein D (2016) Interaction between silicon cycling and straw decomposition in a silicon deficient rice production system. Plant Soil 398(1-2):153-163

Pretty J (1995) The many interpretations of participation. Focus 16:4-5

Reed MS, Stringer LC, Fazey I, Evely AC, Kruijsen JHJ (2014) Five principles for the practice of knowledge exchange in environmental management. J Environ Manag 146:337-345. https://doi. org/10.1016/j.jenvman.2014.07.021

Sattler et al. (this issue) Pesticide diversity in rice growing areas of Northern Vietnam

Settele et al. (this issue) Rice ecosystem services in South-East Asiabackground of and insights from the co-designed and co-produced LEGATO-project

Schneiker J, Weisser WW, Settele J, Sinh NV, Bustamante JV, Marquez L, Villareal S, Arida G, Chien HV, Heong KL, Türke M (2016) Is there hope for sustainable management of golden apple snails, a major invasive pest in irrigated rice? NJAS Wagening J Life Sci 79:11-21

Settele J, Spangenberg JH, Heong KL, Burkhard B, Bustamante JV, Cabbigat J, Chien HV, Escalada MM, Grescho V, Hai LH, Harpke A, Horgan FG, Hotes S, Jahn R, Kühn I, Marquez L, Schädler M, Tekken V, Vetterlein D, Villareal SB, Westphal C, Wiemers M (2015) Agricultural landscapes and ecosystem services in SouthEast Asia-the LEGATO-project. Basic Appl Ecol 16(8):661664. https://doi.org/10.1016/j.baae.2015.10.003

Siew TF, Aenis T, Spangenberg JH, Nauditt A, Döll P, Frank SK, Ribbe L, Rodriguez-Labajos B, Rumbaur C, Settele J, Wang J (2016) Transdisciplinary research in support of land and water management in China and Southeast Asia: evaluation of four research projects. Sustain Sci 11(5):813-829. https://doi.org/10.1007/ s11625-016-0378-0

Spangenberg JH (2011) Sustainability science: a review, an analysis and some empirical lessons. Environ Conserv 38(3):275-287. https://doi.org/10.1017/S0376892911000270

Spangenberg et al. (this issue) Cross-disciplinary research results integrated into an ecosystem service framework-the LEGATO example of integrating research results from the analysis of global change impacts and social, cultural and economic system dynamics of irrigated rice production

Spangenberg JH, Douguet J-M, Settele J, Heong KL (2015a) Locked into continuous insecticide spraying in rice. developing an integrated ecological and socio-political DPSIR analysis. J Ecol Model 295:188-195. https://doi.org/10.1016/j.ecolm odel.2014.05.010

Spangenberg JH, Görg C, Settele J (2015b) Stakeholder involvement in ESS research and governance: between conceptual ambition and practical experiences-risks, challenges and tested tools. Ecosyst Serv 16:201-211. https://doi.org/10.1016/j.ecoser.2015.10.006

Tekken V, Spangenberg JH, Escalada M, Burkhard B, Truong DT, Settele J (2017) "Things are different now": a qualitative assessment of farmer perceptions of cultural ecosystem services of traditional rice landscapes in Vietnam, and the Philippines. Ecosyst Serv 25:153-166. https://doi.org/10.1016/j.ecoser.2017.04.010 
Václavík T, Langerwisch F, Cotter M, Fick J, Häuser I, Hotes S, Kamp J, Settele J, Spangenberg JH, Seppelt R (2016) Investigating transferability potentials of place-based research in land system science. Environ Res Lett 11(9):095002. https://doi. org/10.1088/1748-9326/11/9/095002

Van Sinh et al. (this issue) Lessons from the LEGATO project for the rice cultivation in the North of Vietnam

Westphal C, Vidal S, Horgan FG, Gurr GM, Escalada MM, Chien HV, Tscharntke T, Heong KL, Settele J (2015) Promoting multiple ecosystem services with flower strips and participatory approaches in rice production landscapes. Basic Appl Ecol 16(8):681-689. https://doi.org/10.1016/j.baae.2015.10.004

Wu W, Farooq Shah, Fahad Shah, Huang J (2015) Rice sheath blight evaluation as affected by fertilization rate and planting density. Australas Plant Pathol 44(2):183-189 